\title{
Comparing Traditional and Integrated Curricula on Physiology Knowledge Retention and Application
}

\author{
Fernando, $S .{ }^{1}$, Ellawala, A. $^{2}$ \& Wijayasiri, $A .^{3}$
}

\begin{abstract}
Introduction: The Faculty of Medical Sciences revised its curriculum from traditional, subject-based, to an integrated, system-based one in 2007. This study aimed to assess and compare the ability to retain and apply knowledge in Physiology, among the last batch of students following the traditional curriculum and the first batch following the integrated curriculum.
\end{abstract}

Methods: Twenty true/false type applied Physiology questions from the 2nd year examinations of the two batches were administered separately when the students were in the final year. The marks were compared with those obtained for the same questions at the 2 nd year examination. The difference between the two was considered the retention score. A SAQ comprising applied Physiology questions was also administered to assess application ability and the scores were compared.

Results: A total of 152 and 132 participated from the batches following the traditional and integrated curricula respectively. Both batches displayed a significant loss of knowledge by the final year (negative retention score). The knowledge loss was lower in academically average and high performing students of the integrated curriculum. Students following the integrated curriculum showed significantly higher ability to apply Physiology knowledge to clinical problems.

Conclusion: The students following the integrated curriculum were better in applying physiology knowledge to clinical scenarios and the retention of knowledge was also better among the average and high performing students following the integrated curriculum.

Keywords: Curriculum, knowledge, retention

\section{Introduction}

The Faculty of Medical Sciences, University of Sri Jayewardenepura commenced the MBBS degree programme in 1993 with a traditional, discipline-based curriculum.

${ }^{1}$ Department of Physiology, Faculty of Medical Sciences, University of Sri Jayewardenepura, Nugegoda, Sri Lanka

${ }^{2}$ Department of Medical Education, Faculty of Medical Sciences, University of Sri Jayewardenepura, Nugegoda, Sri Lanka

${ }^{3}$ Department of Community Medicine, Faculty of Medical Sciences, University of Sri Jayewardenepura, Nugegoda, Sri Lanka

Corresponding Author:

Amaya Ellawala

Department of Medical Education, Faculty of Medical Sciences, University of Sri Jayewardenepura, Nugegoda, Sri Lanka.

Email: amaya@sjp.ac.lk
At a time when medical schools around the world were shifting to integrated, studentcentered learning (Ghosh \& Pandya, 2008; Ling et al., 2008; Gahutu, 2010) the faculty too felt the need to change and identified key areas for revision. Overlap of content amongst disciplines, a teacher-centered approach to learning (Lujan \& DiCarlo, 2005), lack of integration of knowledge and effective application of basic sciences knowledge to clinical situations were considered imperative.

An integrated approach to learning and teaching is an accepted and effective educational strategy (Schmidt, 1998; Harden, 2000). The curriculum was revised with horizontal and vertical integration, conducted in three phases. Basic sciences and applied sciences were delivered as organ systembased modules (eg. cardiovascular module), in

DOI: http://doi.org/10.4038/seajme.v13i2.213

(CC) SEAJME. This is an Open Access article distributed under the terms of the Creative Commons Attribution
License (http://creativecommons.org/licenses/by/4.0/), which permits unrestricted use, distribution, and
reproduction in any medium, provided the original author and source are credited


Phase I and Phase II respectively, while Phase III comprised exclusive clinical training in the University Teaching Units of Medicine, Surgery, Paediatrics, Obstetrics and Gynaecology, Psychiatry and Family Medicine. In Phases I and II the assessments were integrated. The revised curriculum focused on the application of knowledge and was more student-centered. These revisions to the curriculum were implemented in 2007.

The main aim of integration of disciplines was to promote retention and application of basic sciences knowledge. Sound basic sciences knowledge is vital for any doctor, as it provides the foundation for diagnosis, investigation, clinical reasoning and management (Zanchetti, 2005; DiLullo et al., 2009). Furthermore, inability to retain knowledge is an identified issue in medical education (Cate et al., 2004), with students themselves admitting a loss of knowledge as the course progresses (D'Eon, 2006). Previous studies have found that a loss of knowledge is inevitable during medical training and that performance on written assessments declines with time (Watt, 1987; Swanson et al., 1996; D'Eon, 2006; Ling et al., 2008). However, there is evidence that an integrated approach to learning and regular reinforcement throughout the course support knowledge retention (D'Eon, 2006).

Integrated medical curricula have been evaluated utilising diverse methods of objective knowledge assessment (Saleh et al., 2004; Vyas et al., 2008). Although previous studies have reported on basic science knowledge retention (Watt, 1987; Swanson et al., 1996; D'Eon, 2006), no studies were found in relation to the local context. This study aimed to assess and compare the level of Physiology knowledge retention and the application among undergraduates following a traditional curriculum and integrated curriculum.

\section{Methods}

The study participants were the students of the last batch following the traditional curriculum (Batch ' $T$ ' [Traditional]) and the first batch to follow the revised integrated curriculum (Batch 'l' [Integrated]).

A True/False (T/F) question paper and a Short Answer Question (SAQ) paper were administered to both batches when they were in the final year of the degree programme. Both papers were administered on the same day under strict examination conditions. Students were given prior notice of the date and any student who wished to opt out of the study was permitted to do so. Neither batch was aware that the marks obtained were to be compared.

The T/F paper comprised 20 questions in Physiology to be answered in one hour. All questions covering the core content were selected by the researchers from the secondyear examinations of each batch (10 questions each). The SAQ paper comprised four applied Physiology questions, to be answered in one hour. After both batches had completed the test, experienced academics in Physiology marked the papers based on a marking scheme. Those marking answers were blinded to the batch of the candidate and the identity of students was not revealed.

The marks obtained in the final year T/F paper administered during the study, were compared with the marks obtained for the same questions in the second year, using the paired t-test. Pearson's correlation coefficient was used to measure the association between marks. The difference between second and final year scores for T/F questions (retention score) was used to measure the ability to retain knowledge, while SAQ scores were used to measure the ability to apply Physiology knowledge. Socio demographic data of students was obtained from the Faculty records with permission from the Dean and were compared. Differences in retention and application ability between groups of varied academic ability (poor, average, high) were assessed. For this purpose, overall second year examination performance and Advanced Level Z score (entry criterion to gain admission to the faculty) were taken as measures of inherent academic ability. Data was analysed using SPSS version 20.0. Table 1 summarises the terms used in the study.

Ethical clearance for the study was obtained from the Ethics Review Committee of the faculty.

\section{Results}

A total of 152 and 132 students participated from batches $T$ and I respectively. In both batches, male: female ratios were approximately 2:3 and majority of students were from the Colombo district. Socioeconomic characteristics of the students of both batches were similar. 
T/F component (Physiology knowledge retention)

In Batch T, $49.2 \%$ of students scored $\geq 50 \%$ in the final year $\mathrm{T} / \mathrm{F}$ paper, with a mean score of 50.32 out of 100 (SD-10.50). The mean score obtained for the 10 questions derived from the second-year examination paper of the same batch, was 26.9 out of 50 (SD-6.04). Comparison of second and final year scores for these 10 questions showed that $28.9 \%$ had scored higher, $4.6 \%$ had scored the same and $66.5 \%$ had scored less in the final year than in their second-year examination (Figure 1).

In Batch I, $81 \%$ of students scored $\geq 50 \%$, with an overall mean score of 53.33 (SD-9.99). The mean score obtained for the questions extracted from their second-year examination paper, was 26.3 (SD-5.53). Comparing second and final year scores for these questions revealed that $59.1 \%$ had scored higher, $4.5 \%$ the same and $36.4 \%$ had scored less in the final year (Figure 1).

The difference between second and final year mean scores (mean retention score), was -3.63 for Batch T and -2.12 for Batch I (Figure 2). The proportion of knowledge loss was $13.49 \%$ and $8.06 \%$ respectively. The difference between second and final year mean scores within each batch was found to be statistically significant. However, the difference between the two batches in this regard, was not significant $(p=0.063)$. A positive correlation was seen between second and final year Physiology scores in both Batch $\mathrm{T}(\mathrm{r}=0.42)$ and Batch $\mathrm{I}$ $(r=0.38)$, which was statistically significant. There was no significant difference between the performance of males and females.

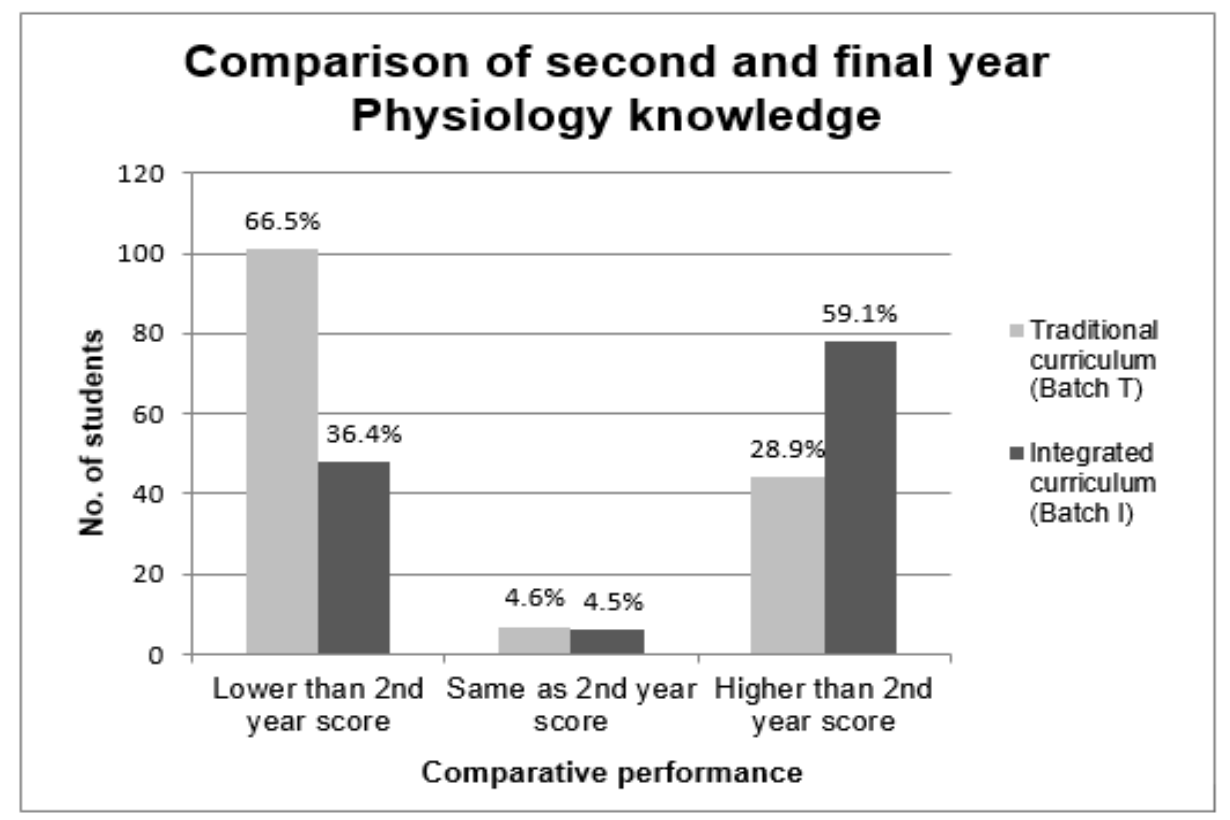

Figure 1: Comparison of second and final year Physiology knowledge

Physiology knowledge retention and the $Z$ score

Overall scores in the final year $T / F$ paper were compared to the GCE Advanced Level Z scores of students. Mean $Z$ scores of each batch were 2.04 (SD-0.11) and 2.11 (SD-0.10) for Batch T and I respectively $(P<0.05)$.

The entire study group was divided according to the pooled median Z score (2.10). Overall, in students who had entered medial faculty with a relatively lower $Z$ score $(<2.10)$, there was no statistically significant difference in mean retention scores between the two batches. Conversely, in the group who had higher Z scores $(\geq 2.10)$, the difference in mean retention scores between the two batches was statistically significant. In both groups, students of Batch I displayed a lower proportion of knowledge loss than those who had followed the traditional curriculum (Figure 3).

The difference between the total $\mathrm{T} / \mathrm{F}$ scores in the final year between the two batches was statistically significant, a finding that was independent of the $Z$ score at entry to medical faculty. 


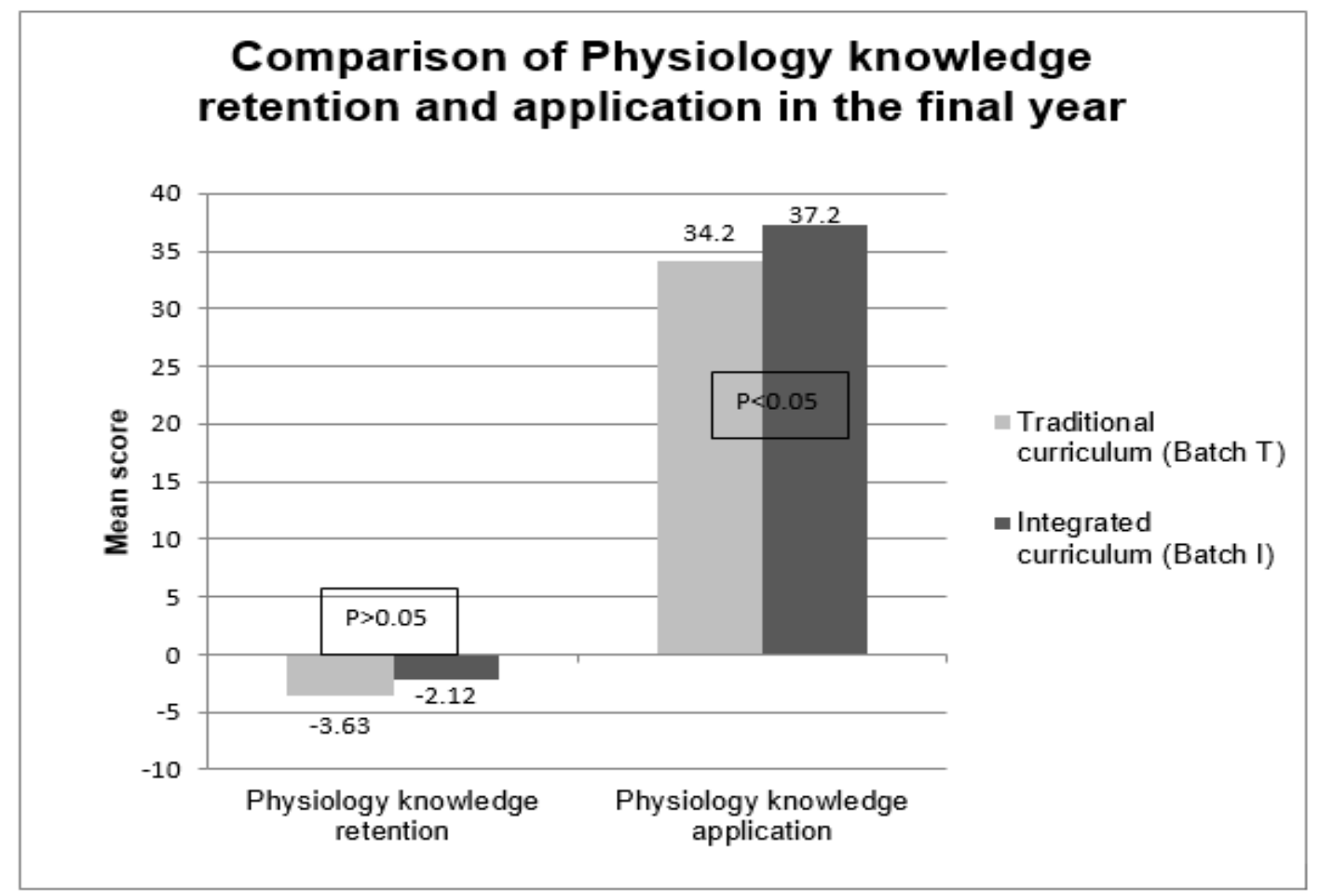

Figure 2: Comparison of Physiology knowledge retention and application in the final year

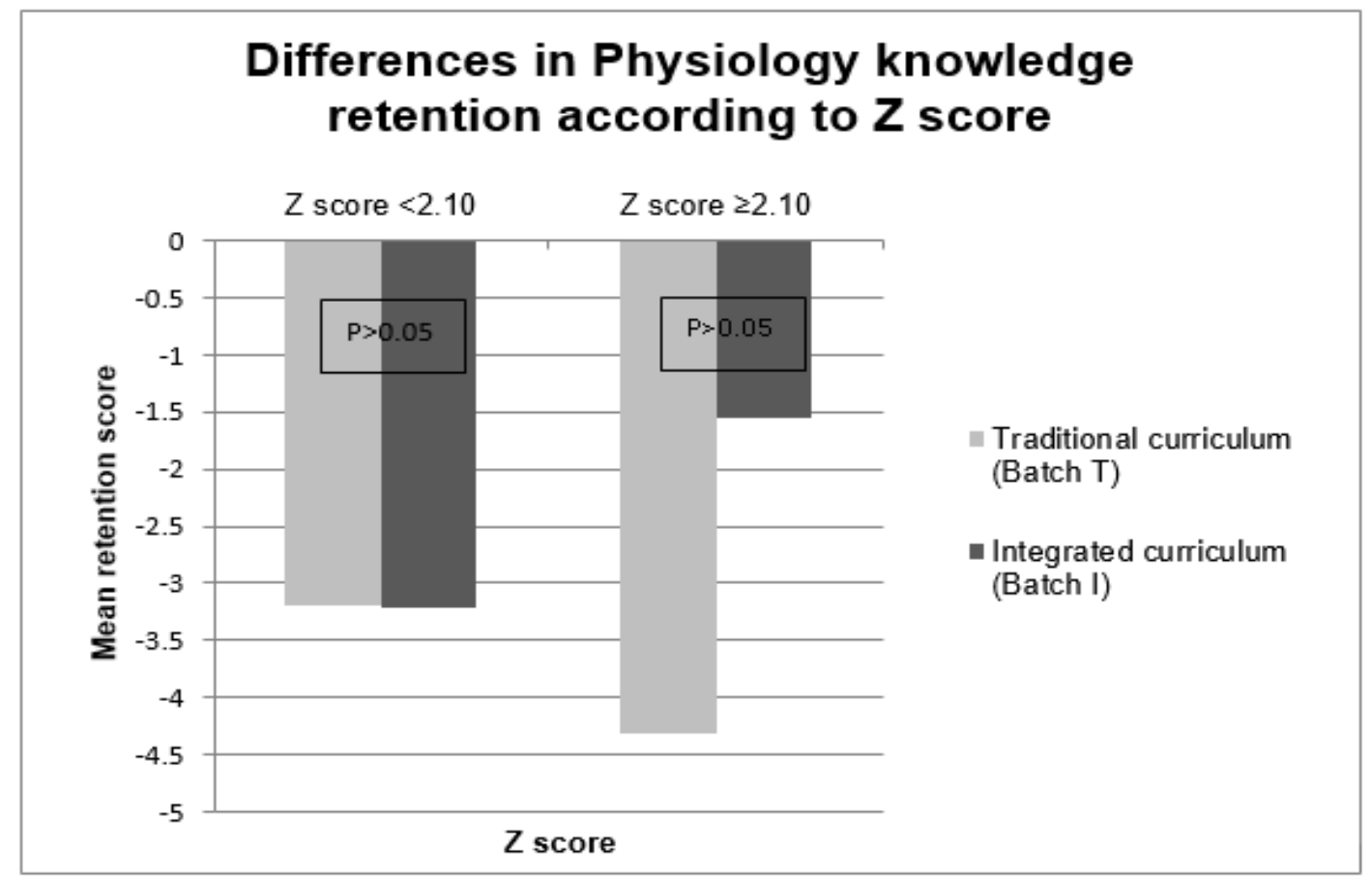

Figure 3: Differences in Physiology knowledge retention according to $Z$ score 
Overall second year examination mean scores and Physiology knowledge retention

The overall second year examination (comprising Anatomy, Biochemistry and Physiology) mean scores of the two batches, were 57.8 (SD-8.49) and 55.8 (SD-7.43) for batches $\mathrm{T}$ and I respectively. The difference between the two was marginally significant $(p=0.04)$.

In order to remove the effect of inherent academic ability on Physiology knowledge retention, the entire study group was stratified into three groups according to overall second year examination performance, which was considered a measure of academic ability. The results are summarised in Table 2 . Among the low performers, students of Batch $\mathrm{T}$ displayed a knowledge gain while Batch I students displayed a loss of knowledge. Average and high-level performers seemed to have 'lost' knowledge from the second to the fifth year. However, within these two groups, students of Batch $T$ showed a larger knowledge loss than those of Batch I. The difference in knowledge retention between students from the two batches, was significant only among averagelevel performers.

\section{SAQ component (Physiology knowledge application)}

For the SAQ paper which tested ability to apply physiology knowledge, the score out of 100 for the students of batch T was 34.2 (SD-8.73) while the score for Batch I was 37.2 (SD-9.45) $(p<0.05)$ (Figure 2).

Table 1: Definitions of terms used in the article

\begin{tabular}{|c|c|}
\hline Term & Definition \\
\hline Final year T/F paper & $\mathrm{T} / \mathrm{F}$ paper administered by researchers in final year \\
\hline Final year SAQ paper & SAQ paper administered by researchers in final year \\
\hline $\begin{array}{l}\text { Level of retention of physiology } \\
\text { knowledge (mean retention score) }\end{array}$ & $\begin{array}{l}\text { Difference between second and final year mean scores } \\
\text { for the } 10 \mathrm{~T} / \mathrm{F} \text { questions selected from the second-year } \\
\text { examination of the respective batch }\end{array}$ \\
\hline \multirow{2}{*}{ Proportion of knowledge loss } & $\begin{array}{c}\text { Difference between second and final year } \\
\text { mean scores for the selected } 10 \mathrm{~T} / \mathrm{F} \\
\text { questions }\end{array}$ \\
\hline & $\begin{array}{c}\text { Second year mean score for selected } 10 \mathrm{~T} / \mathrm{F} \\
\text { questions }\end{array}$ \\
\hline Second year examination & Main examination at the end of the $2^{\text {nd }}$ year \\
\hline Second year Physiology score & Mean score for Physiology in second year examination \\
\hline Final year Physiology $T / F$ score & Mean score for final year T/F paper \\
\hline $\begin{array}{l}\text { Overall second year examination } \\
\text { mean score }\end{array}$ & $\begin{array}{l}\text { Mean score for entire second year examination including } \\
\text { Anatomy, Biochemistry and Physiology }\end{array}$ \\
\hline
\end{tabular}


Table 2: Comparison of Physiology knowledge mean retention scores among students of similar academic ability

\begin{tabular}{|c|c|c|c|c|}
\hline \multirow{2}{*}{$\begin{array}{l}\text { Group (according to } \\
\text { overall second year } \\
\text { examination mean } \\
\text { score) }\end{array}$} & \multicolumn{2}{|c|}{ Mean retention score } & \multirow[b]{2}{*}{ Mean difference } & \multirow[b]{2}{*}{$P$ value } \\
\hline & $\begin{array}{l}\text { Traditional } \\
\text { curriculum }\end{array}$ & $\begin{array}{l}\text { Integrated } \\
\text { curriculum }\end{array}$ & & \\
\hline Low level performers & $\begin{array}{c}2.18 \\
(n=28)\end{array}$ & $\begin{array}{l}-0.54 \\
(n=26)\end{array}$ & 2.72 & 0.120 \\
\hline $\begin{array}{l}\text { Average level } \\
\text { performers }\end{array}$ & $\begin{array}{c}-4.82 \\
(n=72)\end{array}$ & $\begin{array}{c}-2.3 \\
(n=74)\end{array}$ & -2.52 & 0.027 \\
\hline High level performers & $\begin{array}{c}-5.1 \\
(n=52)\end{array}$ & $\begin{array}{c}-3.0 \\
(n=32)\end{array}$ & -2.09 & 0.124 \\
\hline
\end{tabular}

\section{Discussion}

The student groups that followed the traditional and integrated curricula showed a similar distribution of age and gender. The mean $Z$ score, a measure of inherent academic ability, was significantly higher in students of Batch I, though the second-year examination performance, another measure of academic ability, was lower.

Students in the integrated curriculum were comparatively better when assessed in the final year, obtaining a higher mean score for $T / F$ questions $(p<0.05)$ and SAQ papers $(p<0.05)$, with a higher proportion of students scoring $>50 \%$ in the $\mathrm{T} / \mathrm{F}$ paper and displaying retention of knowledge. However, there was a significant overall 'loss' of Physiology knowledge from the second to the final year in students who followed both curricula, though the proportion of knowledge loss in students following the integrated curriculum was comparatively lower $(p>0.05)$. Similar results have been reported in previous studies (Watt, 1987; Swanson et al., 1996; D'Eon, 2006; Ling et al., 2008). The proportion of knowledge loss among students following the traditional curriculum (13.49\%) and integrated curriculum (8.06\%) was also comparable to previous studies (D'Eon, 2006; Ling et al., 2008). The ability of students to apply Physiology knowledge to clinical problems, tested through the SAQ paper, was significantly higher in students of the integrated curriculum. One of the main aims of the curriculum revision was to promote the ability to apply basic sciences knowledge and this aim appears to have been met with the change to an integrated curriculum.

Discussing the perceived effect of entry level academic performance (GCE Advanced Level $Z$ score) on subsequent examination performance of the students is noteworthy. As Batch I have entered medical faculty with a significantly higher average $Z$ score than Batch $\mathrm{T}$, it is possible to attribute their subsequently better final year Physiology knowledge and application ability to this fact. The ability to retain Physiology knowledge does not seem to have an effect on the students with a comparatively lower Z score in both batches irrespective of the method of delivery of content. However, in the group with comparatively higher $Z$ scores, the integrated curriculum appears to have been beneficial in promoting retention of Physiology knowledge.

Another point to consider is the overall second year examination performance of the two groups. Students of Batch T scored significantly higher than those of Batch I overall, though displaying a larger proportion of knowledge loss subsequently. Furthermore, a negative correlation was found between overall second year examination performance and Physiology retention. This is compatible with literature stating that the original score of an examination cannot predict the knowledge loss that would occur subsequently (Conway et al., 1992; D'Eon, 2006). Evidence shows that cramming, while producing high grades initially is 'counter- 
productive in the long term' (Sissons et al., 1992). This is evident in the current study with students following the traditional curriculum performing better overall than the students of integrated curriculum initially (2nd year) but displaying a greater proportion of knowledge loss when assessed in the final year.

A more comprehensive assessment on the differences in retention and application ability would have been achieved with the inclusion of the other two basic sciences disciplines (Anatomy and Biochemistry) in the study. However, based on previous evidence (Koens et al., 2005) it was reasoned that assessing content in Physiology would be more relevant in measuring/gauging clinical application.

The removal of the effect of inherent academic ability on Physiology knowledge retention was challenging when conducting this study. Though the mean knowledge loss was found to be lower in Batch I (-2.12) when compared to Batch T (-3.63) this difference may not be solely attributed to the change in curricula. One of the main factors could be varied levels of intelligence and academic ability of the students in the two batches. Since measurement of academic ability was not feasible, the overall second year examination performance was taken as a proxy. Stratification of the entire study group according to overall second year examination performance enabled comparison of knowledge retention within groups with similar academic performance. While comparatively lower knowledge loss was seen among students of the integrated curriculum in all but the low performing group, the results were significant only among average performers. This could be due however, to the comparatively larger number of subjects falling into this group $(n=146)$. As mentioned previously, among those with higher Z scores (another indicator of academic ability), students from the integrated curriculum showed significantly lower knowledge loss. Considering both these findings collectively, the assumption that the integrated curriculum has a positive effect on enhancing retention ability, at least among the students with average and higher academic ability, is supported.

It is reported that over-learning in the initial phase and subsequent reinforcement through spaced practice are necessary for long-term memory (Halpern, 2003). Therefore, the fact that a significant improvement in retention was not observed with the introduction of an integrated curriculum cannot be attributed solely to the differences in the curriculum design, but to the possibility that the knowledge was not adequately reinforced over time (D'Eon, 2006). It is possible that such reinforcement and continued practice could lead to a significant improvement in knowledge retention as is expected with a curriculum of such nature (Giles et al., 1982).

The long-term impact of revision of the curriculum from a subject based to an integrated one needs to be assessed with more diverse methods over a period of time. The researchers acknowledge that comparing only two groups of students following the two curricula was a limitation in the current study. Factors such as formal peer teaching and individual study patterns that may have influenced retention and application ability were not taken into consideration and is recognised as another limitation of the study.

\section{Conclusion}

In this study, students following both traditional and integrated medical curricula displayed a significant loss of Physiology knowledge from the second to the final year. However, students within the integrated curriculum had better Physiology knowledge and application ability in the final year, than their counterparts following the traditional discipline-based curriculum. The average and high academic performers within the integrated curriculum, showed comparatively better retention of knowledge. The integrated curriculum while enabling the ability to apply Physiology knowledge to clinical problems, also appears to promote the retention of knowledge among students with average and high academic ability.

\section{Conflict of Interest}

The authors declare no conflict of interest.

\section{References}

Cate, O.T., Snell, L., Mann, K. \& Vermunt, J. (2004) Orienting teaching toward the learning process. Academic Medicine, 79, pp. 219-228.

Conway, M.A., Cohen, G. \& Stanhope, N. (1992) Very long-term memory for knowledge acquired at school and university. Applied Cognitive Psychology, 6, pp. 467-482.

D'Eon, M.F. (2006) Knowledge loss of medical students on first year basic science courses at the University of Saskatchewan. BMC Medical Education. 6:5 [online] Available at: http://www.biomedcentral.com/1472-6920/6/5/ [Accessed 28th July 2017]. 
DiLullo C., Morris H.J., Kriebel R.M. (2009) Clinical Competencies and the Basic Sciences: An Online Case Tutorial Paradigm for Delivery of Integrated Clinical and Basic Science Content. Anatomical Sciences Education, 2, pp. 238-243.

EL-Bab, M.F., Sheikh, B., Shalaby, S., El-Awady, M \& Allam, A. (2011) Evaluation of Basic Medical Sciences Knowledge Retention among Medical Students. Ibnosina Journal of Medicine and Biomedical Sciences, 3, 2, pp. 45-52.

Gahutu JB. (2010) Physiology teaching and learning experience in a new modular curriculum at the National University of Rwanda. Advances in Physiology Education, 3, pp. 11-14.

Ghosh, S. and Pandya, H.V. (2008) Implementation of integrated learning program in neurosciences during first year of traditional medical course: Perception of students and faculty. BMC medical education, 8, 1, pp.44.

Giles, R.M., Johnson, M.R., Knight, K.E., Zammett, S. \& Weinman, J. (1982) Recall of lecture information: a question of what, when, and where. Medical Education, 16, pp. 264-268.

Halpern, F.H. (2003) Thought and Knowledge: An introduction to critical thinking (4th ed). New Jersey: Lawrence Erlbaum Associates.

Harden, R.M. (2000) The integration ladder: a tool for curriculum planning and evaluation. Medical Education-Oxford-, 34, 7, pp.551-557.

Koens, F., Rademakers, J.J. \& Ten C.O. (2005) Validation of core medical knowledge by postgraduates and specialists. Medical Education, 39, pp. 911-917.

Ling, Y., Swanson, D.B., Holtzman, K. and Bucak S.D. (2008) Retention of Basic Science Information by Senior Medical Students. Academic Medicine, 83, 10, pp. S82-S85.
Lujan HL., DiCarlo SE. (2005) Too much teaching, not enough learning: what is the solution? Advances in Physiology Education, 30, pp. 1722.

Saleh, K., Messner, R., Axtell, S., Harris, I. and Mahowald, M.L. (2004) Development and evaluation of an integrated musculoskeletal disease course for medical students. JBJS, 86, 8, pp.1653-1658.

Schmidt, H. (1998) Integrating the teaching of basic sciences, clinical sciences and biopsychosocial issues. Academic Medicine, 73, 9, pp. 24-31

Sissons, J.C., Swartz, R.D. \& Wolf, F.M. (1992) Learning, retention and recall of clinical information. Medical Education, 26, pp. 454-461.

Smith, SR. (2005) Toward an integrated curriculum, Medicine and Health Rhode Island [online] Available at:< http://findarticles.com/p/articles/mi_qa4100/is_2 00508/ai_n14898557/> [Accessed 10th May 2017]

Swanson, D.B., Case, S.M., Luecht, R.M. \& Dillon, G.F. (1996) Retention of basic science information by fourth year medical students. Academic Medicine, 71, 10, pp. S80-S82.

Vyas, R., Jacob, M., Faith, M., Isaac, B., Rabi, S., Sathishkumar, S., Selvakumar, D. and Ganesh, A. (2008) An effective integrated learning programme in the first year of the medical course. National Medical Journal of India, 21, 1, pp.21.

Watt, M.E. (1987) Retention of preclinical knowledge by clinical students. Medical Education, 21, pp. 119-124

Zanchetti, A. (2005) The basic importance of the physiological approach in clinical medicine: the experience in the area of hypertension. Archives Italiennes de Biologie, 143, pp. 97-102. 